\title{
Prevalence of voiding and defecatory dysfunction in postmenopausal women with pelvic organ prolapse: a prospective observational study
}

\author{
Nanthini Saravanan', Emily Divya Ebenezer ${ }^{1}$, Vaibhav Londhe', Lilly Varghese', \\ Aruna N. Kekre ${ }^{1 *}$, Vishalakshi Jeyaseelan², Nitin Kekre ${ }^{3}$
}

\begin{abstract}
${ }^{1}$ Department of Obstetrics and Gynecology, ${ }^{2}$ Department of Biostatistics, ${ }^{3}$ Department of Urology, Unit-II, Christian Medical College and Hospital, Vellore, Tamil Nadu, India
\end{abstract}

Received: 14 March 2018

Accepted: 21 April 2018

\section{*Correspondence:}

Dr. Aruna N. Kekre,

E-mail: ankekre@gmail.com

Copyright: () the author(s), publisher and licensee Medip Academy. This is an open-access article distributed under the terms of the Creative Commons Attribution Non-Commercial License, which permits unrestricted non-commercial use, distribution, and reproduction in any medium, provided the original work is properly cited.

\begin{abstract}
Background: Primary objective of this work was to study the prevalence of voiding and defecatory dysfunction in women with pelvic organ prolapse and correlate the stage and compartment of prolapse with voiding and defecatory dysfunction. The secondary objective was to correlate stage of prolapse with flow rate and post void residue and to study the voiding dysfunction in pelvic organ prolapse.

Methods: A prospective observational cohort study in 120 post-menopausal women scheduled for vaginal hysterectomy pelvic floor repair. Short form of pelvic floor distress inventory (PFDI-20) and International prostate symptom questionnaire I-PSS score for Lower urinary tract symptoms (LUTS)was employed.

Results: The prevalence of voiding dysfunction in this study was $78 \%$ and defecatory dysfunction was $77 \%$. Higher stage of prolapse had significant correlation with voiding dysfunction. (P value was 0.028). Women with posterior compartment defect had more voiding dysfunction with the significant $\mathrm{P}$ value ( $\mathrm{p}$ value was 0.04). Pre-operative voiding dysfunction resolved post operatively in $86 \%$, the $\mathrm{p}<0.000$ which was highly significant.

Conclusions: Women with pelvic organ prolapse had high prevalence of voiding and defecatory dysfunction. Stages of prolapse have positive correlation with voiding dysfunction. Pre-operative voiding dysfunction resolved after vaginal hysterectomy and pelvic floor repair.
\end{abstract}

Keywords: Defecatory dysfunction, Pelvic organ prolapse, Post-menopausal, Post void residue, Uroflowmetry, Voiding dysfunction

\section{INTRODUCTION}

Pelvic organ prolapse (POP), is defined by the international continence society as the the symptomatic descent of the anterior vaginal wall, the posterior vaginal wall, the apex of the vagina or the vaginal vault. ${ }^{1}$ Women with POP may presents with symptoms of urinary incontinence, fecal incontinence, voiding dysfunction, and defecatory dysfunction, this interrelated group of conditions collectively describe as "Disorders of the Pelvic Floor". 2 This study aims to understand the prevalence and relationship between pelvic organ prolapse and voiding dysfunction and defecatory dysfunction. The available outcome of these measures can be used by clinicians and researchers to assess the functional outcomes of prolapse and its treatment on patients with an emphasis on symptom and quality-of-life assessment. 


\section{METHODS}

Postmenopausal women with POP admitted for surgery in the Gynaecology department of Christian Medical College and Hospital, Vellore, India between October 2015 to April 2017 were invited to participate in the present study. Postmenopausal women with Stage 2, 3 and 4 POP and Vault prolapse were included in the study. Women with neurological disorder and prior antiincontinence or bowel surgery were excluded from the study.

The institutional review board and the ethics committee of the Christian Medical College approved the study. The details and nature of the study were explained to all participants and written informed consent was obtained before the study began. Socio demographic and clinical details were collected using a structured interview. Short form of pelvic floor distress inventory (PFDI-20) and International prostate symptom questionnaire I-PSS score for Lower urinary tract symptoms (LUTS) was also employed.

All subjects underwent through pelvic examination. Prolapse was staged as per the POP-Q classification, 24 hours voiding diary was maintained, Uroflowmetry was undertaken, and postvoid residual urine volume was measured within 10 minutes of voiding using a trans abdominal scan. A sample size of 120 was calculated using a prevalence of POP of $40 \%$. and a precision of $10 \%$, with the computer program EPI Info version 3.1 (Centers for Disease Control and Prevention, Atlanta, GA, USA). All the categorical variables were associated with voidal dysfunction using Chi-square test with continuity correction and for small sample size Fisher's exact test was used. All those significant in the Chisquare test or independent $\mathrm{t}$-test at $\mathrm{p} \leq 0.2$ were taken for logistic regression analysis. SPSS version 21 was used for analysis and $\mathrm{p}<0.05$ was considered as statistically significant. $^{3}$

\section{RESULTS}

A total of 120 postmenopausal women were recruited in this prospective observational cohort study. Prevalence of Voiding dysfunction was $78 \%$ and defecatory dysfunction was $77 \%$. The mean age of these women was 58 years, Body mass index (BMI) $26 \mathrm{Kg} / \mathrm{m}^{2}$ and parity was 3 . The mean duration of menopause was 142 months and duration of prolapse was 53 months. $24.2 \%(n=29)$ of women had diabetes, $25 \%(\mathrm{n}=30)$ had hypertension and $4 \%(n=5)$ had chronic cough (Table 1$)$.

The preoperative maximum flow rate was $19.2 \mathrm{ml} / \mathrm{sec}(\mathrm{Q}$ $\max 19.2 \mathrm{ml} / \mathrm{sec}$ ) and after pelvic reconstructive surgery maximum flow rate improved to $25.3 \mathrm{ml} / \mathrm{sec}$ (Q $\max 25.3$ $\mathrm{ml} / \mathrm{sec}$ ). Preoperative PVR was $108 \mathrm{ml}$ and postoperative patients voided freely with a post void residue of $57.03 \pm 44.50 \mathrm{ml}$. Over all prevalence of voiding dysfunction was $78 \%$ (Table 2).
Table 1: Demographic and clinical data $(n=120)$.

\begin{tabular}{|ll|}
\hline Patient Characteristics & Participants $(\mathrm{n}=120)$ \\
\hline Age $(\mathrm{years})^{\mathrm{a}}$ & $58 \pm 8.7$ \\
\hline BMI $\left(\mathrm{kg} / \mathrm{m}^{2}\right)^{\mathrm{b}}$ & $26 \pm 4.8$ \\
\hline Parity ${ }^{\mathrm{a}}$ & $3 \pm 0.46$ \\
\hline $\begin{array}{l}\text { Duration of menopause } \\
\text { (months) }^{\mathrm{a}}\end{array}$ & $142 \pm 108$ \\
\hline $\begin{array}{l}\text { Duration of prolapse } \\
\text { (months) }\end{array}$ & a \\
$\begin{array}{l}\text { a Values are given as mean } \pm \text { SD. or percentage (numbers), unless } \\
\text { indicated otherwise }\end{array}$ \\
$\begin{array}{l}\mathrm{b} \text { Calculated as weight in kilograms divided by the square of } \\
\text { height in meters. }\end{array}$ \\
\hline
\end{tabular}

Table 2: Voiding dysfunction $(n=120)$.

\begin{tabular}{|ll|}
\hline Patient Characteristics ${ }^{\text {a }}$ & Participants $(\mathrm{n}=120)$ \\
\hline Pre op Q max $(\mathrm{ml} / \mathrm{sec})$ & $19.2 \pm 7.9$ \\
\hline Pre op PVR $(\mathrm{ml})$ & $108 \pm 67.9$ \\
\hline Post op Q $\max (\mathrm{ml} / \mathrm{sec})$ & $25.3 \pm 5.7$ \\
\hline Post OP PVR $(\mathrm{ml})$ & $57.03 \pm 44.50$ \\
\hline Voiding dysfunction & $78.3(94)$ \\
\hline $\begin{array}{l}\text { a Values are given as mean } \pm \text { SD. } \\
\text { unless indicated otherwise }\end{array}$ & Or percentage (numbers), \\
\hline
\end{tabular}

Table 3: Stages and compartments of prolapse $(n=120)$.

\begin{tabular}{|ll|}
\hline Patient Characteristics & Participants $(\mathrm{n}=120)$ \\
\hline Stage II POP & $5.8(7)$ \\
\hline Stage III POP & $80(96)$ \\
\hline Stage IV POP & $14.2(17)$ \\
\hline Anterior compartment & $98.3(118)$ \\
\hline Posterior compartment & $82.5(99)$ \\
\hline Apical compartment & $92.5(111)$ \\
\hline Point Aa $(\mathrm{cm})$ & $1.92 \pm 1.48$ \\
\hline Point $\mathrm{Ba}(\mathrm{cm})$ & $3.3 \pm 1.75$ \\
\hline Point Ap $(\mathrm{cm})$ & $-0.6 \pm 2.06$ \\
\hline Point Bp $(\mathrm{cm})$ & $0.30 \pm 2.46$ \\
\hline${ }^{a}$ Values are given as mean \pm SD. & Or percentage (numbers), \\
unless indicated otherwise &
\end{tabular}

$5.8 \%$ women $(n=7)$ had stage II, $80 \%(n=96)$ had stage III prolapse and $14.2 \% \quad(\mathrm{n}=17)$ IV POP. Anterior compartment defect was identified in $98.3 \% \quad(n=118)$, posterior compartment in $82.5 \% \quad(n=99)$ and apical compartment in $92.5 \%(\mathrm{n}=111)$. The mean POP-Q points were point $\mathrm{Aa}=1.9 \mathrm{~cm}$ point $\mathrm{Ba}=3.3 \mathrm{~cm}$ The posterior compartment point measurements of point $A p=-0.6 \mathrm{~cm}$ and $\mathrm{BP}=-0.30 \mathrm{~cm}$ (Table 3). Voiding dysfunction was defined as presence of at least one of the following criteria Maximal flow rate $($ Qmax $)<15 \mathrm{ml} / \mathrm{s}$ or $P V R \geq 100 \mathrm{ml}$. The prevalence of voiding dysfunction in stage II, Stage III and stage IV prolapse were $85.7 \%$ $(\mathrm{n}=6), 74 \%(\mathrm{n}=71)$ and $100 \%(\mathrm{n}=17)$ respectively.with significant $\mathrm{P}$ value $(\mathrm{p}=0.028)$. The prevalence of voiding 
dysfunction in the anterior compartment prolapse was $78.8 \%(\mathrm{n}=93)$, posterior $81.8 \% \quad(\mathrm{n}=81)$ and apical compartment was $78.4 \%(n=87)$. Though women with anterior compartment prolapse had voiding dysfunction with the odds ratio of 3.72 (95\% CI=0.23-61.59). Women with posterior compartment had more voiding dysfunction with Odds ratio of 2.77 (95\% CI $=1.00-7.66)$ and the calculated $P$ value was significant $(\mathrm{p}=0.044)$. The mean value of POP-Q point with voiding dysfunction in point Aa was $2 \pm 1.5$, Point Ba 3.5 \pm 1.4 , Point Ap $-0.7 \pm 2.3$ and Point $\mathrm{Bp}$ was $0.3 \pm 2.8$. However, statistical significance could not be obtained (Table 4).

Table 4: Correlation of stages, compartment and POPQ points with voiding and defecatory dysfunction.

\begin{tabular}{|c|c|c|c|c|c|c|c|c|c|c|}
\hline \multicolumn{6}{|c|}{ Voiding dysfunction } & \multicolumn{5}{|c|}{ Defecatory Dysfunction } \\
\hline & $\begin{array}{l}\text { Present } \\
(\%)\end{array}$ & $\begin{array}{l}\text { Absent } \\
(\%)\end{array}$ & $\begin{array}{l}P \\
\text { value }\end{array}$ & OR & CI $(95 \%)$ & $\begin{array}{l}\text { Present } \\
(\%)\end{array}$ & $\begin{array}{l}\text { Absent } \\
(\%)\end{array}$ & $\begin{array}{l}P \\
\text { value }\end{array}$ & OR & CI $(95 \%)$ \\
\hline \multicolumn{11}{|c|}{ Stage of prolapse \% (n) } \\
\hline Stage II & $85.7(6)$ & $14.3(1)$ & \multirow{4}{*}{0.028} & & & $71.4(5)$ & $28.6(2)$ & \multirow{4}{*}{0.531} & & \\
\hline Stage III & $74(71)$ & $26(25)$ & & & & $76(73)$ & $24(23)$ & & & \\
\hline Stage IV & $100(17)$ & 0 & & & & $88.2(15)$ & $11.8(2)$ & & & \\
\hline Total & $78.3(94)$ & $21.7(26)$ & & & & $77.5(93)$ & $22.5(27)$ & & & \\
\hline \multicolumn{11}{|c|}{ POPQ points $(\mathrm{cm}) \pm$ SD } \\
\hline Point Aa & $2 \pm 1.5$ & $1.8 \pm 1.5$ & 0.73 & & & $1.9 \pm 1.4$ & $1.7 \pm 1.7$ & 0.47 & & \\
\hline Point $\mathrm{Ba}$ & $3.5 \pm 1.4$ & $3.2 \pm 1.8$ & 0.4 & & & $3.2 \pm 1.7$ & $3.3 \pm 1.9$ & 0.81 & & \\
\hline Point Ap & $-0.7 \pm 2.3$ & $-0.6 \pm 1.9$ & 0.77 & & & $-0.4 \pm 2.1$ & $-1.3 \pm 1.9$ & 0.06 & & \\
\hline Point Bp & $0.3 \pm 2.8$ & $0.3 \pm 2.3$ & 0.88 & & & $0.5 \pm 2.5$ & $-0.3 \pm 2.3$ & 0.13 & & \\
\hline \multicolumn{11}{|c|}{ Compartment } \\
\hline $\begin{array}{l}\text { Anterior } \\
(\mathrm{n}=118)\end{array}$ & $78.8(93)$ & $21.2(25)$ & 0.388 & 3.72 & $0.23-61.59$ & $78(92)$ & $22(26)$ & 0.401 & 3.538 & $0.21-58.52$ \\
\hline $\begin{array}{l}\text { Posterior } \\
(n=99)\end{array}$ & $81.8(81)$ & $18.2(18)$ & 0.044 & 2.77 & $1.00-7.66$ & $81.8(81)$ & $18.2(18)$ & 0.021 & 3.375 & $1.23-9.21$ \\
\hline $\begin{array}{l}\text { Apical } \\
(\mathrm{n}=111)\end{array}$ & $78.4(87)$ & $21.6(24)$ & 1.00 & 1.04 & $0.20-5.31$ & $79.3(88)$ & $20.7(23)$ & 0.114 & 3.061 & $0.760-12.32$ \\
\hline
\end{tabular}

LUTS was studied using International prostate symptom score. $57.1 \%(n=4)$ of stage II, $74 \%(n=71)$ of stage III and $88.2 \%(n=15)$ of stage IV POP showed a IPSS score higher than 20 indicating severe lower urinary tract symptoms. However the $\mathrm{P}$ value was not significant $(\mathrm{p}=0.175)$. Quality of life issues studied according to the international prostate symptom score showed that 92.7 $(n=89)$ of women in stage III POP had unsatisfactory quality of life compared to $88.2 \%$ (15) in stage IV and $71.4 \%(5)$ in stage II POP. (P value of 0.130 which was not significant).

Defecatory dysfunction was defined as "patients who gave positive response for 2 or more questions out of 8 questions" in CRADI-8 bowel subscale score with in PFDI-20 (short form of the pelvic floor distress inventory). The overall prevalence of defecatory dysfunction in this study was $77 \%(\mathrm{n}=93)$. In stage IV pelvic organ prolapse $88.2 \% \quad(n=15)$ had defecatory dysfunction compared to $71 \%(\mathrm{n}=4)$ in stage II POP and $76 \%(n=73)$ in stage III pelvic organ prolapse. However, $\mathrm{P}$ value was not significant $(\mathrm{p}=0.531)$.

In posterior compartment defect $82 \%(n=81)$ of women had defecatory dysfunction compared to $78 \%(n=92)$ with anterior and $79 \%(n=88)$ with apical compartment defect. Women with posterior compartment defect had more defecatory dysfunction with significant $p$ value $(\mathrm{p}=0.021)$.

The mean value of POP-Q point in $\mathrm{cm}$ were point Aa 1.9, Point Ba 3.2, Point Ap -0.4 and Point Bp 0.5. However, statistical significance could not be obtained (Table 4). $78 \%$ of women in this study had pre-operative voiding dysfunction $(\mathrm{n}=94)$, In $86.2 \%(\mathrm{n}=81)$ of women voiding dysfunction resolved after vaginal hysterectomy with pelvic floor repair and $11.5 \%(\mathrm{n}=3)$ of women developed voiding dysfunction after vaginal hysterectomy with pelvic floor repair, with a $\mathrm{P}$ value which was highly significant $(\mathrm{p}<0.000)$ (Table 5).

Table 5: Correlation of pre-operative voiding dysfunction with post-operative voiding dysfunction.

\begin{tabular}{|c|c|c|c|}
\hline Preop VD & $\begin{array}{l}\text { Post op VDa } \\
\text { Yes }\end{array}$ & $\begin{array}{l}\text { Post op VDa } \\
\text { No }\end{array}$ & $P$ value \\
\hline Yes(n=94) & $13.8(13)$ & $86.2(81)$ & \multirow{2}{*}{$<0.000$} \\
\hline No $(n=26)$ & $11.5(3)$ & $88.5(23)$ & \\
\hline
\end{tabular}

${ }^{a}$ Values are given as mean \pm SD. or percentage (numbers), unless indicated otherwise. 


\section{DISCUSSION}

Pelvic organ prolapse is a common problem in women and particularly in menopausal women having negative impact on quality of life. The mean prevalence of pelvic organ prolapse were about $19.7 \%$ in the Indian subcontinent. The lifetime risk of undergoing an operation for POP/incontinence by $80 \mathrm{yrs}$ is $11.1 \% .^{4}$

'Voiding dysfunction' (VD) as per international continence society is defined as a diagnosis by symptoms and uroflometry investigations as abnormally slow and/or incomplete micturition. ${ }^{5}$ In this study we defined Voiding dysfunction as Q $\max <15 \mathrm{ml} / \mathrm{sec}$ or PVR $>100 \mathrm{ml}$.

'Defecatory dysfunction' is characterized by a spectrum of anatomic and functional abnormalities that can lead to fecal incontinence or incomplete evacuation. In this study the defecatory dysfunction was defined as "the patients who gave positive response for 2 or more questions out of 8 questions" in CRADI- 8 bowel subscale score with in PFDI-20 (short form of the pelvic floor distress inventory). Romanzi et al studied the effect of genital prolapse on voiding dysfunction and reported that women with stage III and IV POP had more voiding dysfunction compared to lesser degree of prolapse (44\% vs. $9 \%){ }^{6}$ In this study the overall prevalence of pre-operative Voiding dysfunction was $78 \%$. Women with stage II and III and IV prolapse the Voiding dysfunction was reported in $85.7 \%, 74 \%$ and $100 \%$ respectively. Stage IV POP had more voiding dysfunction with the statistically significant $p$ value $(p=0.028)$. The possible explanation could be urethral kinking and obstruction. ${ }^{3}$

chae et al. reported the POP-Q stage specially the anterior compartment prolapse had greater incidence of voiding dysfunction compared to posterior and apical compartments with significant $P$ value $(p=0.018) .^{3}$ In this study though women with anterior compartment prolapse had voiding dysfunction with the odds ratio of $3.72(95 \%$ $\mathrm{CI}=0.23-61.59)$. Women with posterior compartment had more voiding dysfunction with Odds ratio of $2.77(95 \%$ $\mathrm{CI}=1.00-7.66)$ and the calculated $\mathrm{p}$ value was significant $(p=0.044)$. A possible explanation for this finding may be that the prolapse of the anterior wall compartment produces pressure more directly on the urethra through a buttressing effect. ${ }^{3}$ In this study the overall prevalence of defecatory dysfunction was $77 \%$. In stage II, stage III and stage IV prolapse the presence of defecatory dysfunction was reported in $71.4 \%(n=5), 76 \%(n=73), 88.2 \% \quad(n=15)$ respectively. The $\mathrm{P}$ value 0.531 was not significant.

Ellerman et al had found a significant correlation between posterior compartment prolapse and defecatory dysfunction. $^{7}$ Similarly, in this study women with posterior compartment defect have more defecatory dysfunction with significant $\mathrm{p}=0.021$. A possible explanation for this finding may be that the prolapse of the posterior wall compartment produce an anatomic redundancy of the rectum in to the vagina (rectocele) or perineum (perineocele) resulting in more defecatory dysfunction. Posterior compartment defect leads to splinting and sense of incomplete evacuation. ${ }^{7}$ The International prostate symptom score was validated in postmenopausal women for evaluating lower urinary tract symptoms. $^{8}$

A study done by Obinata et. al. showed the severity of IPSS total scores significantly correlated with preoperative POP-Q stage and the total of $37 \%$ of stage 4 showed $\geq 20$ IPSS. ${ }^{9}$ In our study a total of $57.1 \%(n=4)$ of stage II,74\% ( $n=71)$ of stage III and $88.2 \%(n=15)$ of stage IV POP showed $\geq 20$ International Prostate Symptom Score (severe LUTS). However, the $\mathrm{P}$ value was not significant $(p=0.175)$. Various studies in the literature supports that the advanced stage of prolapse have negative impact on QOL. ${ }^{10,11}$ In contrast, we observed that $92.7 \%$ (89) of women in stage III POP had unsatisfied quality of life compared to $88.2 \%$ (15) in stage IV and $71.4 \%$ (5) in stage II POP. However the P value was not significant $(\mathrm{p}=0.130)$ due to small numbers in stage IV POP.

Studies have reported a reduced flow rate and High PVR in women with high stage of POP. A study by Romanzi et al showed $72 \%$ of women with advanced prolapse had low mean and Q max compared to $6 \%$ in stage I or II prolapse. ${ }^{6}$ In this study it was noticed $58.8 \%(n=10)$ stage IV had pre-operative Qmax $<15 \mathrm{ml} / \mathrm{sec}$, which was completely resolved after vaginal hysterectomy with pelvic floor repair. In stage III $35.4 \%(n=34)$ had preoperative Qmax $<15 \mathrm{ml} / \mathrm{sec}$, in which complete resolution was achieved in that $95.8 \%(n=30)$.

A study by Romanzi et al reported $30 \%$ of women with stage 3 or 4 prolapse have elevated post void residuals. ${ }^{6}$ Similarly $43(n=3)$ in stage II, 66\% $(n=63)$ in stage III POP and $82.4 \%(\mathrm{n}=14)$ had elevated pre-operative PVR which resolved post operatively in $85.7 \%(\mathrm{n}=2)$ in stage II, $92.7 \%(n=56)$ in stage III POP and $76.2 \%(n=10)$ in stage IV POP. Nguyen et al studied the resolution of motor urge incontinence after surgical repair of pelvic organ prolapse and reported the detrusor instability resolved after vaginal reconstructive surgery in $63 \% .{ }^{12}$ In this study a total of $78 \%(n=94)$ of women had preoperative voiding dysfunction, of which $86.2 \%(n=81)$ of women had resolution of voiding dysfunction after vaginal hysterectomy with pelvic floor repair.

$11.5 \%(n=3)$ of women developed voiding dysfunction after vaginal hysterectomy with pelvic floor repair, with a $P$ value which was highly significant $(p<0.000)$. As all of the voiding symptoms and PVR and Q max were significantly improved, after surgery voiding difficulty might be relieved after pelvic reconstructive surgery by restoring the anatomy. ${ }^{12}$

A study done by Chae et al showed POP-Q points Aa and $\mathrm{Ba}$ were significantly longer in women with voiding dysfunction. ${ }^{3}$ In contrast to the above, the present study 
showed that the POP-Q points $\mathrm{Aa}$ and $\mathrm{Ba}$ did not correlate with voiding dysfunction. $P$ values $(p=0.73 \&$ $\mathrm{p}=0.4$ ) not significant.

Collins et al studied the correlation of POP-Q posterior compartment measures with defecatory dysfunction and found the POP-Q Bp point, but not perineal body measurement correlated with defecatory dysfunction. ${ }^{13}$ In contrast in our study the posterior compartment POP-Q points point $\mathrm{Ap}$ and point $\mathrm{Bp}$ were not correlated with defecatory dysfunction $\mathrm{p}$ value not significant.

Management of POP aims at restoring anatomy, restoring function and improving the quality of life. Voiding and defecatory dysfunction is not life threatening, but has a negative impact on quality of life. Though majority of voiding and defecatory dysfunction regress after restoring the pelvic anatomy, some may still persist or patients may have denovo voiding dysfunction for which Patients should be counselled prior to surgery.

In summary, the overall prevalence of voiding dysfunction in this study was $78 \%$ and the defecatory dysfunction was $77 \%$. The stage of the prolapse correlated with voiding dysfunction,the prevalence of voiding dysfunction in stage II, Stage III and stage IV prolapse were $85.7 \%(n=6), 74 \%(n=71)$ and $100 \%$ $(n=17)$ respectively.with significant $\mathrm{p}$ value $(\mathrm{p}=0.028)$ Though women with anterior compartment prolapse had voiding dysfunction with the odds ratio of $3.72(95 \%$ $\mathrm{CI}=0.23-61.59)$. ( $\mathrm{P}$ value 0.338 not significant $)$. Women with posterior compartment had more voiding dysfunction with Odds ratio of 2.77 (95\% CI $=1.00-7.66)$ and the calculated $\mathrm{p}$ value was significant $(\mathrm{p}=0.044)$.

Women with posterior compartment defect had more defecatory dysfunction with the significant $p$ value $(p=0.021)$. Stage of POP did not correlate with severity of LUTS, (p value 0.175 was not significant) and with QOL, ( $\mathrm{P}$ value 0.130 was not significant). The POP-Q Points not correlated with voiding or defecatory dysfunction. Preoperative voiding dysfunction resolved post operatively in $86.3 \%$ and $11.5 \% \quad(n=3)$ of women developed voiding dysfunction after vaginal hysterectomy with pelvic floor repair, $(p<0.000$ was highly significant).

Funding: The study was funded by fluid research grant project from the Christian Medical College, Vellore, India (IRB No.9690 dated 20.10.2015)

Conflict of interest: None declared

Ethical approval: The study was approved by the Blue Research and Ethics Committee, Christian Medical College, Vellore, India

\section{REFERENCES}

1. Lowder JL, Ghetti C, Nikolajski C, Oliphant SS, Zyczynski HM. Body image perceptions in women with pelvic organ prolapse: a qualitative study. Am J Obstet Gynecol. 2011;204:441.e1-441.e5.

2. Jackson S, Weber A, Hull T, Mitchinson A, Walters M. Fecal incontinence in women with urinary incontinence and pelvic organ prolapse. Obstet Gynecol. 1997;89:423-7.

3. Chae JY, Park GY, Kim JH, Kim HJ, Bae JH, Lee JG, et al. Points $\mathrm{Aa}$ and $\mathrm{Ba}$ are factors associated with preoperative voiding dysfunction in patients with cystocele. Eur J Obstet Gynecol Reprod Biol. 2014;174:146-9.

4. Olsen A, Smith V, Bergstrom J, Colling J, Clark A. Epidemiology of surgically managed pelvic organ prolapse and urinary incontinence. Obstet Gynecol 1997;89:501-6.

5. Hendrix SL, Clark A, Nygaard I, Aragaki A, Barnabei V, McTiernan A. Pelvic organ prolapse in the women's health initiative: Gravity and gravidity. Am J Obstet Gynecol. 2002;186:1160-6.

6. Romanzi LJ, Chaikin DC, Blaivas JG. The effect of genital prolapse on voiding. J Urol. 1999;161:581-6.

7. Saks EK, Harvie HS, Asfaw TS, Arya LA. Clinical significance of obstructive defecatory symptoms in women with pelvic organ prolapse. Int J Gynecol Obstet. 2010;111:237-40.

8. Pott-Grinstein E, Newcomer JR. Gynecologists' patterns of prescribing pessaries. J Reprod Med. 2001;46:205-8.

9. Obinata D, Yamaguchi K, Ito A, Murata Y, Ashikari D, Igarashi $\mathrm{T}$, et al. Lower urinary tract symptoms in female patients with pelvic organ prolapse: Efficacy of pelvic floor reconstruction: LUTS in POP patients and TVM \pm TOT. Int J Urol. 2014;21:301-7.

10. Okamura K, Nojiri Y, Osuga Y, Tange C. Psychometric Analysis of International Prostate Symptom Score for Female Lower Urinary Tract Symptoms. Urology. 2009;73:1199-202.

11. Scarpero HM, Fiske J, Xue X, Nitti VW. American Urological Association Symptom Index for lower urinary tract symptoms in women: correlation with degree of bother and impact on quality of life. Urology. 2003;61:1118-22.

12. Nguyen JK, Bhatia NN. Resolution of motor urge incontinence after surgical repair of pelvic organ prolapse. J Urol. 2001;166:2263-6.

13. Collins SA, O'Sullivan DM, Lasala CA. Correlation of POP-Q posterior compartment measures with defecatory dysfunction. Int Urogynecology J 2012;23:743-7.

Cite this article as: Saravanan N, Ebenezer ED,

Londhe V, Varghese L, Kekre AN, Jeyaseelan V.

Prevalence of voiding and defecatory dysfunction in postmenopausal women with pelvic organ prolapse: a prospective observational study. Int J Reprod Contracept Obstet Gynecol 2018;7:2230-4. 